"Investigating the use of business, competitive and marketing intelligence as management tools in the mining industry"

$\begin{array}{ll}\text { AUTHORS } & \begin{array}{l}\text { Dinko Herman Boikanyo } \\ \text { Ronnie Lotriet } \\ \text { Pieter W. Buys }\end{array} \\ & \text { Dinko Herman Boikanyo, Ronnie Lotriet and Pieter W. Buys (2016). Investigating } \\ \text { the use of business, competitive and marketing intelligence as management tools } \\ \text { in the mining industry. Problems and Perspectives in Management, 14(2), 27-35. } \\ \text { doi:10.21511/ppm.14(2).2016.03 }\end{array}$

DOI $\quad$ http://dx.doi.org/10.21511/ppm.14(2).2016.03

RELEASED ON

Wednesday, 11 May 2016

JOURNAL

"Problems and Perspectives in Management"

FOUNDER

LLC "Consulting Publishing Company "Business Perspectives"

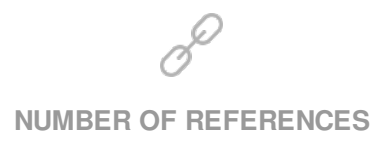

0
NUMBER OF FIGURES

0
靖

NUMBER OF TABLES

0

(C) The author(s) 2022. This publication is an open access article. 
Dinko Herman Boikanyo (South Africa), Ronnie Lotriet (South Africa), Pieter W. Buys (South Africa)

\title{
Investigating the use of business, competitive and marketing intelligence as management tools in the mining industry
}

\begin{abstract}
The main objective of this research study is to investigate the extent to which business intelligence, competitive intelligence and marketing intelligence are used within the mining industry. Business intelligence, competitive intelligence and marketing intelligence are the management tools used to mine information to produce up-to-date intelligence and knowledge for operative and strategic decision making.

A structured questionnaire is used for the study. A total of 300 mines are randomly selected from a research population of mining organizations in South Africa, Africa and globally. The respondents are all part of senior management. A response rate of $64 \%$ is achieved. The results indicat that more than half of the respondents do not have real-time intelligence and proper data mining tools to identify patterns and relationships within a data warehouse. Although a large proportion agrees that their organizations have systematic ways of gathering these different types of intelligence and use them for strategic decision making, there is a significant proportion that did not have any systems.
\end{abstract}

Statistically and practically significant positive relationships with a large effect are found among the dimensions of business intelligence, marketing intelligence, competitive intelligence and perceived business performance.

Keywords: business intelligence, competitive intelligence, marketing intelligence, mining industry.

JEL Classification: M10, M15.

\section{Introduction}

This study focuses on investigating the use of business intelligence, competitive intelligence and marketing intelligence in the mining industry. A background to the research study will be provided to enable the framing of the research focus. Subsequently, the research objectives and an overview of the research methodology will be presented. The results of the empirical study will, thereafter, be reported. Finally, the conclusion resulting from the study will be discussed, as well as any recommendations that can be made to management and for future studies.

\section{Background}

According to Igbaekemen (2015), reliable data and information form the basis of any strategic management decision and also for all the investigative and analytical efforts of managers. Obtaining accurate and reliable relevant information promptly from both external and internal sources can assist in anticipating, identifying, analyzing and resolving or preventing problems. The environment within which organizations operate is also changing at an

(c) Dinko Herman Boikanyo, Ronnie Lotriet, Pieter W. Buys, 2016. Dinko Herman Boikanyo, B.Sc., MBA, scientist in a petrochemical industry, strategic sourcing and marketing function for a mining organization in South Africa, Ph.D. candidate, North-West University, Potchefstroom campus, South Africa.

Ronnie Lotriet, D.Comm., M.Comm. (cum laude), Professor, programme manager for MBA flagship programme, as well as Fundamental Management Program (Executive Education), North-West University, Potchefstroom campus, South Africa.

Pieter W. Buys, M.Comm., MBA, Ph.D. (Accountancy and Management Accountancy), Professor, research program director at the North-West University, US Certified Management Accountant (CMA), North-West University, Potchefstroom campus, South Africa. accelerating rate, so there is a pressing need for realtime intelligence and information. This research focuses on three constructs of intelligence which are defined below.

According to Troy Media (2015), business intelligence (BI) is the analysis of the organization's internal data. $\mathrm{BI}$ is about gathering large amounts of raw data concerning all aspects of business, from profits and losses to productivity, and converting them into actionable insights. Organizations use business intelligence to make improvement to current processes, products and services, as well as identify and develop new opportunities. Coker (2014) views business intelligence as the means by which an organization collects its own information about customers, returning clients, sales or website hits and transforms the numbers into measurable metrics to ascertain that the organization is performing efficiently. BI depends mainly on technology, using applications and processes to analyze the (mostly internal) data. One of the main benefits of $\mathrm{BI}$ is that it permits the organizations to contextualize both historical and current data, which enables them to make better and informed predictions. It is also critical for effective measurement of benchmarks or performance metrics. Organizations have also realized that BI gives them an opportunity to gain insight and enhance decision-making capabilities to assist other organizations in uncovering new opportunities, improving efficiency and achieving strategic goals (Gartner, 2013). BI has applications across all levels of an organization, from research and development, product development and pricing to staffing and strategic planning process improvement (Troy Media, 2015). 
While business intelligence focuses, to a large extent, on the organization's internal data, competitive intelligence focuses mainly on the external factors that affect the operation. Competitive intelligence (CI) means looking at the state of the competitive environment, in which the organization operates, to identify trends and detect potential threats, as well as points of possible differentiation (Pellissier \& Nenzhelele, 2013, p. 5).

According to Anica and Cucui (2009) and Troy Media (2015), competitive intelligence usually involves looking thoroughly at the competitors, and assessing their strengths and weaknesses to identify possible opportunities. CI involves taking the information that has been gathered and converting it into actionable insights to gain competitive advantage - for example, analyzing poor performance of a rival in a certain market can provide information about what not to do and generate some ideas for a successful market penetration strategy. CI practitioners emphasize that in order for data to be considered as real and true competitive intelligence, it has to be actionable. It is also of utmost importance to differentiate between competitive intelligence and corporate or competitive espionage. Competitive intelligence is completely legal and is collected using publicly available information. Corporate espionage or collecting information about the rivals via questionable ways (such as hacking, posing as a potential customer or poaching employees) is not only unethical, but also illegal, in most instances.

According to Kotler et al. (2009), marketing intelligence (MI) is industry-targeted intelligence which is developed on real-time dynamic features of competitive developments happening among the 4Ps of the marketing mix (pricing, place, promotion and product) in the market-place to assist in understanding the attractiveness of the market. MI is the information related to organization's markets, collected and examined specifically for a correct and well-informed decision making in formulating strategy in areas such as market opportunity, market penetration strategy, and market development.

The problem statement is discussed below.

\section{Problem statement}

Mining organizations across the globe face significant challenges, putting the industry at a crossroad. The pressure on these mining organizations is great for them to be efficient, productive and remain profitable in spite of challenges such as volatile commodities market (Deloitte, 2014). Lack of credible information and knowledge of decisions taken by all stakeholders within the mining organizations has led to the weakening and even failure of some of these mines. A lot of data are produced continuously at a site of the mine. Without a proper and systematic way to organize these data and present them in a timely, simplified, easily accessible and accurate manner, tactical and strategic decisions regarding the operations and long term sustainability of a mine site become very challenging (Mining Weekly, 2013). Some mining organizations are still not capable of reading the competitive trends and forces affecting the industry. Some mines cannot benefit from any form of intelligence, because it is not integrated, organized, processed and available to the right people in a format for decision making. There are isolated pools of data which are mainly influenced by the functional view of the business units rather than a broader, general management view of the whole mining organization. Some managers have limited access to corporate-wide data and mental models transformed into information and knowledge upon which they can effectively act with agility. Decisions are, in some cases, made on an event-by-event basis as opposed to being made within a set of strategic parameters (Buthelezi, 2013).

According to Kumari (2013), business intelligence is needed to evaluate the cost-benefit of existing and new operations and technologies, as well as to forecast future technological and operational discontinuities. Competitive intelligence is required to assess the development of competitive strategy over time through changes in competitors' structure, new product substitutes and new industry. Marketing intelligence is also needed by mine managers to provide the means of assessing the current and future trends in customers' preferences and needs, new markets and creative segmentation opportunities together with the main shifts in marketing and distribution.

There is a scarcity in empirical literature about the use of different types of intelligence in the mining sector. This prompted the research to investigate the use of business intelligence, marketing intelligence and competitive intelligence and how they contribute to business performance in the sector. This study will not only aim to improve understanding of these different types of intelligence, but also produce findings of practical relevance and value for the mining and other sectors. Therefore, this research seeks to contribute to both management practitioners and academics alike.

The research objectives of the study are outlined below.

\section{Research objectives}

The primary aim of this research study is to investigate the extent to which business intelligence, competitive intelligence and marketing intelligence 
are utilized within the mining industry. The secondary objectives are:

- To empirically assess a correlation between business performance of the organization and the dimensions of business intelligence, competitive intelligence plus marketing intelligence.

- To determine the demographic differences in terms of geographic location of the organization.

The research methodology used for this study is discussed below.

\section{Research methodology}

4.1. Research design and sample. A survey design was used in which a selected sample was studied to make inferences about the population. The survey involved selecting a representative and unbiased sample of subjects drawn from senior management in the mining organizations in South Africa, Africa and globally. The researcher used a simple random sampling technique to select participants. Saunders et al. (2009) state that simple random sampling involves the selection of a sample at random from the sampling frame using either random number tables or a computer. A total of 300 mines were randomly selected from a population of 850 . A response rate of $64 \%$ was achieved.

The survey questions were developed based on the existing literature with some questions adopted from a questionnaire from a study by Kruger (2010). The structured questionnaire used was divided into sections comprising the biographic information, items of business intelligence, competitive intelligence, marketing intelligence and perceived business performance which were measured using a 4-point Likert-type scale.

4.2. Statistical analysis. The data received from the completed questionnaires were captured and analyzed with the use of the statistical software program SPSS and STATISTICA with the assistance of the Statistical Consulting Services of the North-West University. Descriptive statistics and effect sizes were used to decide on the significance of the findings. The results are to be compared by way of mean and standard deviations. Confirmatory Factor Analysis (CFA) was used to verify the factor structure of the set of variables. Cronbach's Alphas were computed to assess the reliability of the measuring instrument. Pearson product-moment correlation coefficients were calculated to identify the relationships between the variables. The statistical significance level is set at a $95 \%$ confidence interval $(\mathrm{p} \leq 0.05)$. The cut-off point of 0.30 is used to determine practical significance of a medium effect. ANOVA was employed to determine differences between the groups in the sample.

\section{Presentation and discussion of results}

The results of the empirical study are reported and discussed below. Firstly, the results from the biographical questionnaire are discussed and, secondly, an interpretation of the data from the instrument used is presented.

Biographical information was reported for number of employees in the organization, level of employment, type of metal mined or processed, number of years the organization has been operating, and the geographic location.

A total of 193 questionnaires were received representing a response rate of $64 \%$.

The majority of the respondents were working for the mines with more than 1000 employees $(66 \%)$ followed by those in smaller operations with less than 499 employees (18\%). The respondents from medium sized mines with 500 to 999 employees were about $16 \%$.

The majority of respondents were managers $(57 \%)$ followed by directors (34\%) and CEOs (9\%).

About $51 \%$ of the respondents were from the mines producing precious metals such as gold and platinum group metals. A number $(17 \%)$ of the respondents were from coal mining organizations, while about $11 \%$ were from the steel industry. About $12 \%$ were from the mines producing nonferrous metals such as copper and only $8 \%$ were in the industrial metal mines.

The majority of the respondents were from the mines with more than 20 years in operation (87\%), which serves as a confirmation that most of the mines in the world have been operating for decades. Most of the respondents were from the South African mining operations $(55 \%)$, other respondents were from the rest of Africa (23\%), while the respondents from other continents such as USA and Australia formed only about $21 \%$ of all the respondents.

The results of descriptive statistics are presented in the next section.

6.1. Descriptive statistics. 6.1.1. Business intelligence. One of the main objectives of this study was to measure the extent of the use of the business intelligence by the mining organizations. The results are presented in Table 1 . The mean score for item F1 is above 3 indicating that about $75 \%$ of the mining organizations systematically collect information to assist in strategic decision making. The standard deviation for the question was relatively high indicating a high spread in terms of the responses. A significant number (25\%) responded negatively to this question. 
The mean score for responses to item F2 was also above 3 indicating that the majority (72\%) of the participants agree that the availability of business intelligence has, to a certain extent, increased the effectiveness of decision making by the managers. A high standard deviation is also found for this item indicating a relatively large spread in terms of the responses. $28 \%$ of the participants responded negatively to this question. The mean scores for questions F3 and F4 are 2.96 and 2.98, respectively. These mean scores are close to 3 and also indicate that most of the participants responded positively to these questions. Thus, the majority of the mining organizations have business intelligence tools which are used to manipulate data and also have some form of forecasting capabilities. About $20 \%$ of the organizations do not have such business intelligence tools or use them for these specific functions.

Table 1. Results of the questionnaire on business intelligence

\begin{tabular}{|l|l|c|c|c|c|c|c|}
\hline \multicolumn{2}{|c|}{} & $\begin{array}{c}\text { Strongly } \\
\text { disagree }\end{array}$ & $\begin{array}{c}\text { Slightly } \\
\text { disagree }\end{array}$ & $\begin{array}{c}\text { Slightly } \\
\text { agree }\end{array}$ & $\begin{array}{c}\text { Strongly } \\
\text { agree }\end{array}$ & Mean & $\begin{array}{c}\text { Std. } \\
\text { deviation }\end{array}$ \\
\hline F1 & Information is systematically collected to assist in strategic decision making & 13.5 & 11.9 & 32.1 & 42.5 & 3.04 & 1.043 \\
\hline F2 & $\begin{array}{l}\text { The availability of business intelligence has increased the effectiveness of } \\
\text { managerial decision making }\end{array}$ & 8.8 & 19.2 & 25.9 & 46.1 & 3.09 & 1.001 \\
\hline F3 & $\begin{array}{l}\text { Business intelligence tools are used to manipulate data, e.g., operational or/and } \\
\text { historical data }\end{array}$ & 9.3 & 14.0 & 47.7 & 29.0 & 2.96 & .898 \\
\hline F4 & The business intelligence tools have forecasting capabilities & 7.3 & 10.4 & 59.1 & 23.3 & 2.98 & .794 \\
\hline F5 & Data gathered from business intelligence deployment is reliable & 7.8 & 1.6 & 70.5 & 20.2 & 3.03 & .728 \\
\hline F6 & $\begin{array}{l}\text { Knowledge generated from successful business intelligence deployment can be } \\
\text { used to sustain competitive advantage }\end{array}$ & 3.1 & 10.4 & 57.5 & 29.0 & 3.12 & .711 \\
\hline
\end{tabular}

Source: compiled by authors from survey results.

About $91 \%$ of the respondents agree that the data they gathered from BI deployment are reliable. However, about $9 \%$ completely disagree and believe that the data are not reliable. The mean score of 3.12 for the last question indicates that most $(87 \%)$ of the participants agree that the knowledge generated from the deployment of BI systems can be used to sustain competitive advantage.

In general, a large proportion of the participants responded positively to the questions about business intelligence. This indicates that most of the mining organizations are using some form of business intelligence in their strategic decision making.

The other objective of this study was to measure the extent of the use of competitive intelligence by the mining organizations. The results are presented and discussed below.

6.1.2. Competitive intelligence. The results of the questionnaire which was measuring responses for competitive intelligence in the mining organizations are presented in Table 2.

Table 2. Results of the questionnaire on competitive intelligence

\begin{tabular}{|l|l|c|c|c|c|c|c|}
\hline \multicolumn{2}{|l|}{} & $\begin{array}{c}\text { Strongly } \\
\text { disagree }\end{array}$ & $\begin{array}{c}\text { Slightly } \\
\text { disagree }\end{array}$ & $\begin{array}{c}\text { Slightly } \\
\text { agree }\end{array}$ & $\begin{array}{c}\text { Strongly } \\
\text { agree }\end{array}$ & $\begin{array}{c}\text { Mean } \\
\text { deviation }\end{array}$ \\
\hline G1 & The company collects useful information about the competitors & 3.6 & 7.8 & 65.3 & 23.3 & 3.083 & 0.674 \\
\hline G2 & The company collects useful information about the competitive environment & 3.6 & 7.8 & 47.2 & 41.5 & 3.266 & 0.757 \\
\hline G3 & Competitive analysis is conducted in a coordinated manner by various units & 14.0 & 39.4 & 29.0 & 17.6 & 2.505 & 0.943 \\
\hline G4 & Competitive intelligence is used in decision making processes to improve performance & 4.7 & 11.9 & 65.3 & 18.1 & 2.974 & 0.697 \\
\hline G5 & $\begin{array}{l}\text { The company has the ability to determine the future intent of a competitive force on } \\
\text { which the strategies are based }\end{array}$ & 18.7 & 13.0 & 62.7 & 5.7 & 2.563 & 0.854 \\
\hline G6 & Competitive analysis is used to create a competitive advantage & 9.8 & 14.0 & 58.5 & 17.6 & 2.839 & 0.831 \\
\hline G7 & Competitive analysis is focused upon the strategic requirements of the company & 5.7 & 8.3 & 64.8 & 21.2 & 3.026 & 0.712 \\
\hline G8 & The competitive intelligence is distributed to management in a timely fashion & 17.6 & 30.6 & 36.8 & 15.0 & 2.49 & 0.954 \\
\hline G9 & Management is up to date with emerging technologies in their field of business & 8.8 & 11.9 & 57.0 & 22.3 & 2.938 & 0.823 \\
\hline G10 & The organization is cognisant of government legislation and legislative trends that impact it & 4.2 & 2.6 & 38.5 & 54.7 & 3.438 & 0.742 \\
\hline G11 & $\begin{array}{l}\text { There is an organized effort to channel all information about competitive forces to a } \\
\text { central repository }\end{array}$ & 14.0 & 22.8 & 50.3 & 13.0 & 2.625 & 0.883 \\
\hline
\end{tabular}

Source: compiled by authors from survey results.

The mean score for question G1 is above 3 with a relatively low standard deviation. This implies that a large proportion $(89 \%)$ of the respondents agree that their mining organizations collect useful information about their competitors. A similar number $(89 \%)$ of the respondents also agreed that their organizations collect useful information about the competitive environment.

The mean score for question G3 is 2.5 with a relatively high spread. This is because $53 \%$ of the 
participants responded negatively to this question. Thus, more than half of the respondents do not agree that various units do competitive analysis in a coordinated manner.

In spite of a mean score of 2.9 for question G4, a large proportion $(83 \%)$ agrees that $\mathrm{CI}$ is used in decision making processes to improve the performance of their organizations. This is in agreement with $76 \%$ who agree that competitive analysis is used to create some form of competitive advantage for their organizations. The majority of the participants also agreed that competitive analysis is focused on the strategic requirements of their organizations.

The mean score for question G8 is 2.49 with a relatively high spread of the response values. This is due to the fact that $48 \%$ of the participants responded negatively to this question. This implies that almost half of the respondents do not agree that $\mathrm{CI}$ is delivered to management in a timely fashion. Thus, they believe that managers do not receive information as quickly as they should.

A large proportion (79\%) of the respondents agreed that their managers are up to date with emerging technologies in their field of business. The responses also imply that $21 \%$ of the managers are not up to date.

About $93 \%$ of the mining organizations are cognisant of government legislation and legislative trends that affect their businesses. The mean score for question G11 is relatively low (2.6). In spite of this, the majority $(63 \%)$ of the participants agreed that there is an organized effort within their organizations to channel all the information about the competitive forces to a central repository. However, a significant number (37\%) responded negatively to this question.

The other objective of this study was to measure the extent of the use of marketing intelligence by the mining organizations. The results are presented and discussed below.

6.1.3. Marketing intelligence. The results of the questionnaire which was measuring responses for marketing intelligence in the mining organizations are presented in Table 3.

About $70 \%$ of the participants responded positively to question $\mathrm{H} 1$ with a mean score of 2.788 . This means that a large proportion of the respondents agree that their organization has a systematic way of gathering marketing intelligence. About 30\% responded negatively implying that their organization has no systematic way of gathering marketing intelligence. A large proportion $(79 \%)$ of the respondents also agreed that market analysis is used to identify key threats and opportunities. The majority of the respondents also agreed that marketing intelligence is used to understand the nature of the market requirements and also help their organizations to keep abreast of the ongoing emerging circumstances. Almost $20 \%$ of the respondents did not agree. The resulting information of the marketing intelligence contributes to the decision making process, according to about $74 \%$ of the respondents who responded positively to this question. However, 26\% of the participants responded negatively.

Table 3. Results of the questionnaire on marketing intelligence

\begin{tabular}{|l|l|c|c|c|c|c|c|}
\hline \multicolumn{2}{|c|}{} & $\begin{array}{c}\text { Strongly } \\
\text { disagree }\end{array}$ & $\begin{array}{c}\text { Slightly } \\
\text { disagree }\end{array}$ & $\begin{array}{c}\text { Slightly } \\
\text { agree }\end{array}$ & $\begin{array}{c}\text { Strongly } \\
\text { agree }\end{array}$ & $\begin{array}{c}\text { Mean } \\
\text { deviation }\end{array}$ \\
\hline H1 & The organization has a systematic way of gathering of marketing intelligence & 7.3 & 22.8 & 53.9 & 16.1 & 2.788 & 0.798 \\
\hline H2 & Market analysis is used to identify key threads or opportunities & 7.8 & 13.0 & 35.8 & 43.5 & 3.15 & 0.926 \\
\hline H3 & $\begin{array}{l}\text { Marketing intelligence is used to help the company grow (to increase revenue, profit, or } \\
\text { market share) }\end{array}$ & 9.8 & 6.7 & 55.4 & 28.0 & 3.016 & 0.863 \\
\hline H4 & Marketing intelligence is used in understanding the nature of the market requirements & 9.8 & 8.8 & 34.2 & 47.2 & 3.187 & 0.961 \\
\hline H5 & $\begin{array}{l}\text { Marketing intelligence helps the organization to keep abreast of the ongoing emerging } \\
\text { circumstances }\end{array}$ & 5.7 & 17.6 & 28.5 & 48.2 & 3.192 & 0.924 \\
\hline H6 & The resulting information of the marketing intelligence contributes to the decision-making process & 6.7 & 19.7 & 30.1 & 43.5 & 3.104 & 0.946 \\
\hline H7 & Marketing intelligence is distributed to management in a timely fashion & 13.0 & 25.4 & 43.5 & 18.1 & 2.668 & 0.921 \\
\hline H8 & There is an organized effort to channel all information about the markets to a central repository & 20.2 & 24.9 & 34.7 & 20.2 & 2.549 & 1.03 \\
\hline
\end{tabular}

Source: compiled by authors from survey results.

The mean score for question $\mathrm{H} 7$ is relatively low with a large spread. This is due to the fact that $38 \%$ of the participants responded negatively to this question and disagreed that $\mathrm{MI}$ is distributed to management timeously. The mean score for question $\mathrm{H} 8$ is also low with a high spread of the response values. About $45 \%$ of the participants responded negatively to this question and disagreed that there is an organized effort to channel all the information about the markets to a central repository. The other objective of this study was to measure the extent of the use of information systems by the mining organizations. The results are presented and discussed below.

6.1.4. Information systems. The results of the questionnaire which was measuring responses for information systems in the mining organizations are presented in Table 4. 
Table 4. Results of the questionnaire on information systems

\begin{tabular}{|l|l|c|c|c|c|c|c|}
\hline \multicolumn{2}{|c|}{} & $\begin{array}{c}\text { Strongly } \\
\text { disagree }\end{array}$ & $\begin{array}{c}\text { Slightly } \\
\text { disagree }\end{array}$ & $\begin{array}{c}\text { Slightly } \\
\text { agree }\end{array}$ & $\begin{array}{c}\text { Strongly } \\
\text { agree }\end{array}$ & $\begin{array}{c}\text { Mean } \\
\text { deviation }\end{array}$ \\
\hline M1 & The company's management information system provides easy access to data & 1.0 & 11.9 & 70.5 & 16.6 & 3.021 & 0.571 \\
\hline M2 & Intelligence data are integrated across various corporate applications & 10.9 & 22.8 & 60.6 & 5.7 & 2.613 & 0.759 \\
\hline M3 & Technical abilities of the IT staff related to intelligence are good & 11.4 & 19.2 & 47.2 & 22.3 & 2.801 & 0.919 \\
\hline M4 & There are Extraction-Transformation-Load (ETL) tools for data transfer & 23.3 & 16.6 & 56.0 & 4.1 & 2.408 & 0.895 \\
\hline M5 & Data warehouses are used as repository for all data relevant to an organization & 21.2 & 15.5 & 61.7 & 1.6 & 2.435 & 0.843 \\
\hline M6 & $\begin{array}{l}\text { On-Line Analytical Processing (OLAP) techniques are used to analyze and report data } \\
\text { from huge data sources }\end{array}$ & 15.5 & 14.5 & 69.4 & .5 & 2.550 & 0.758 \\
\hline M7 & $\begin{array}{l}\text { The organization has data mining tools to identify patterns and relationships within a data } \\
\text { warehouse and create detailed reports }\end{array}$ & 17.1 & 29.0 & 43.5 & 10.4 & 2.476 & 0.899 \\
\hline M8 & The organization has real-time intelligence capabilities & 27.7 & 25.1 & 38.2 & 8.9 & 2.283 & 0.970 \\
\hline
\end{tabular}

Source: compiled by authors from survey results.

A mean score of 3.02 with a standard deviation of 0.57 was obtained for question M1. About $87 \%$ of the respondents agreed that the information system in their organization provides easy access to data. Only $13 \%$ responded negatively to this question.

The mean for question M2 was relatively low due to the fact that almost $34 \%$ of the participants responded negatively indicating that the intelligence data are not integrated across various corporate applications in their organizations. About $69 \%$ of the respondents believed that the technical abilities of their IT staff related to intelligence are good whereas $31 \%$ believed their skills were not good enough. The rest of the questions had low mean score due to the following:

- About $40 \%$ of the respondents indicated that their organizations do not have ETL tools for data transfer.
- About $37 \%$ of the participant responded negatively to question M5 indicating that data warehouses are not used as repository for all data relevant to their organization.

- About $30 \%$ of the respondents do not use OLAP techniques in the organizations.

- About $46 \%$ of the respondents do not have proper data mining tools to identify patterns and relationships within a data warehouse.

- More than half $(53 \%)$ of the respondents indicated that their organizations do not have real-time intelligence.

The data for the perceived business performance of the organizations are presented and discussed below.

6.1.5. Perceived business performance. The results for the overall business performance are shown in Figure 1.

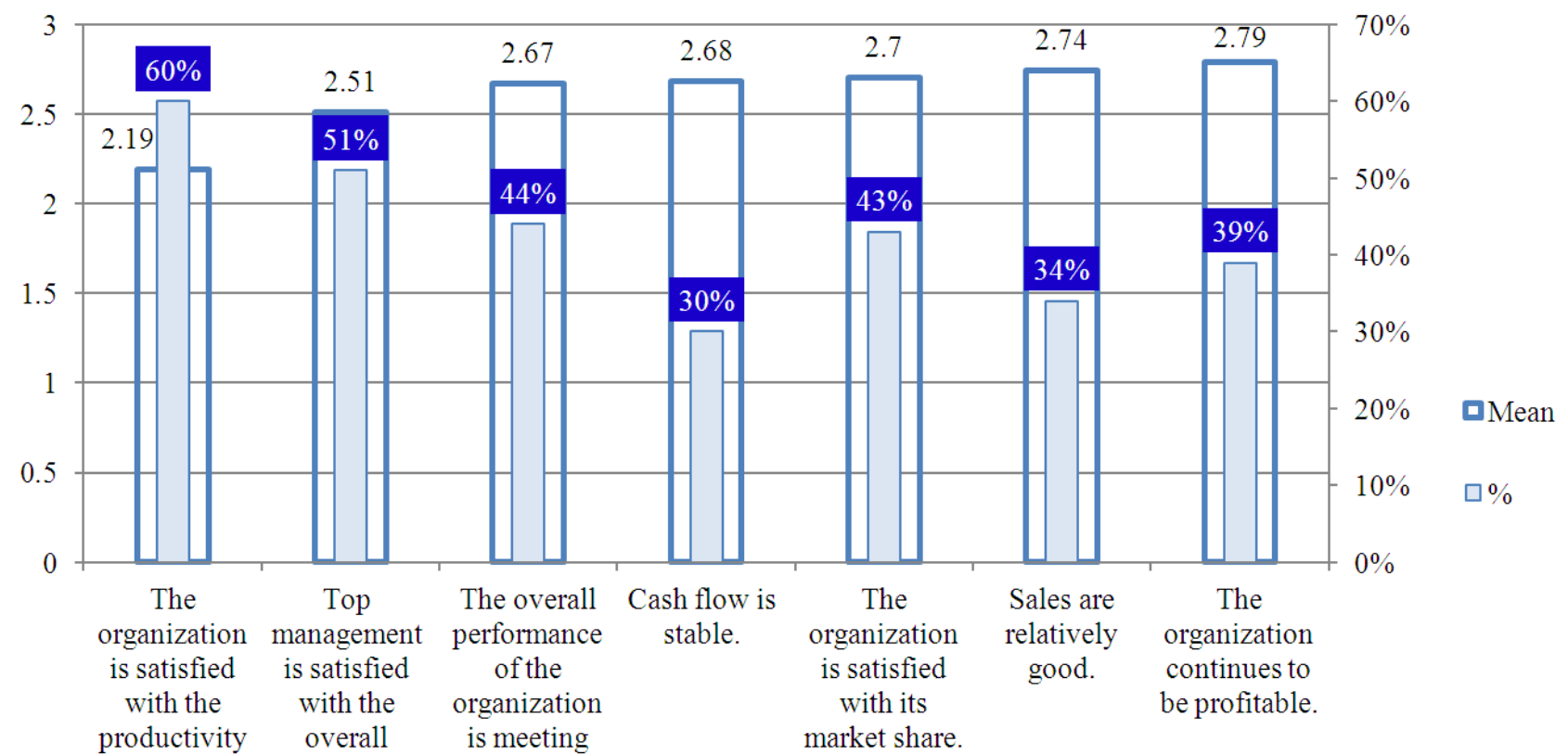

of the current performance. expectations.

operation(s).

Fig. 1. Mean scores in ranking order for perceived business performance

Source: compiled by authors from survey results. 
About $60 \%$ of the organizations were not satisfied with the productivity of their current operations. Top management was not satisfied with overall performance in $51 \%$ of the organizations. The overall performance of $44 \%$ of the mines was not meeting expectations, this is in agreement with the $39 \%$ whose organizations were not profitable. $43 \%$ of the mines were not satisfied with their current market share. A significant number $(30 \%)$ of the mines indicated that their cash flows were not stable at all.

The other objective was to confirm the factor reliability of the dimensions which were used. The results are shown in the following section.
6.2. Factor analysis. An instrument is said to have high reliability if it can be trusted to give an accurate and consistent measurement of an unchanging value. Reliability was calculated and evaluated by means of Cronbach's Alpha. Sekaran and Bougie (2010) suggest that the Cronbach's Alpha coefficient should be greater than 0.70 , for the data to be regarded as reliable and internally consistent. Factor reliability of the identified dimensions is presented in Table 5.

All the factors display satisfactory levels of reliability with Alpha coefficients ranging from 0.90 to 0.96 .

Table 5. Results of factor reliability

\begin{tabular}{|l|c|c|c|c|c|c|c|}
\hline \multicolumn{1}{|c|}{ Factor } & Cronbach's Alpha & Cronbach's Alpha based on standardized items & N of items & Mean & Minimum & Maximum & Variance \\
\hline Business intelligence & 0.900 & 0.908 & 6 & 3.039 & 2.964 & 3.124 & 0.004 \\
\hline Competitive intelligence & 0.943 & 0.946 & 11 & 2.886 & 2.490 & 3.438 & 0.099 \\
\hline Marketing intelligence & 0.959 & 0.959 & 8 & 2.957 & 2.549 & 3.192 & 0.064 \\
\hline Business performance & 0.946 & 0.946 & 7 & 2.613 & 2.192 & 2.788 & 0.042 \\
\hline Information systems & 0.916 & 0.917 & 8 & 2.573 & 2.283 & 3.021 & 0.0564 \\
\hline
\end{tabular}

Source: compiled by authors from survey results.

The number of items loaded on each factor are shown in the Table. The mean values are also shown. The highest mean score was obtained for business intelligence indicating that the largest proportion of participants responded positively to the items of this factor. The lowest mean was obtained for the information systems factor as it had the highest number of negative responses.

The other main objective is to determine if there are any positive relationships among the different constructs of intelligence and the performance of those organizations. The results of those correlations are shown and discussed below.

6.3. Correlations. The results of the productmoment correlation coefficients between the constructs are reported in Table 6.

Table 6. Correlation coefficients between intelligence and business performance dimensions

\begin{tabular}{|l|c|c|c|c|}
\hline & $\begin{array}{c}\text { Business } \\
\text { performance }\end{array}$ & $\begin{array}{c}\text { Business } \\
\text { intelligence }\end{array}$ & $\begin{array}{c}\text { Competitive } \\
\text { intelligence }\end{array}$ & $\begin{array}{c}\text { Market } \\
\text { intelligence }\end{array}$ \\
\hline $\begin{array}{l}\text { Business } \\
\text { performance }\end{array}$ & 1.000 & $.796^{\star \star}$ & $.723^{\star *}$ & $.826^{\star *}$ \\
\hline $\begin{array}{l}\text { Business } \\
\text { intelligence }\end{array}$ & $.796^{\star *}$ & 1.000 & $.877^{\star *}$ & $.878^{\star *}$ \\
\hline $\begin{array}{l}\text { Competitive } \\
\text { intelligence }\end{array}$ & $.723^{\star *}$ & $.877^{\star *}$ & 1.000 & $.826^{\star *}$ \\
\hline $\begin{array}{l}\text { Marketing } \\
\text { intelligence }\end{array}$ & $.826^{\star *}$ & $.878^{\star *}$ & $.826^{\star *}$ & 1.000 \\
\hline
\end{tabular}

**. Correlation is significant at the 0.01 level (2-tailed). Source: compiled by authors from survey results.

The Table shows that business intelligence dimension is positively correlated to business performance (practically significant, large effect). Marketing intelligence is positively correlated to business performance (practically significant, large effect). Competitive intelligence is positively correlated to business performance (practically significant, large effect). All the dimensions of intelligence are positively correlated to the overall business performance of the organization (practically significant, large effect).

The other objective of this study was to compare the findings based on the demographic differences. This was achieved by using the ANOVA tools to establish if there were any significant differences in the responses based on the biographical information of the participants. The results are discussed below.

6.4. Differences according geographic location. The data indicated that mines in other continents have relatively higher means implying that they use these different types of intelligence more than those in SA and the rest of Africa. Lowest means were observed for mining organizations in Africa.

\section{Conclusions}

Conclusions regarding the specific theoretical objectives and the results of the empirical study are made.

Conclusions regarding the specific theoretical objectives. To answer the first objective of the study with regard to the conceptualization of different types of intelligence, from the literature review, the following came out. 
Business intelligence technologies give historical, current and predictive insight of business operations and use technologies, processes and applications to examine mostly internal, structured data and business processes, whereas competitive intelligence collects, assesses and disseminates information with a topical focus on the rivals. Competitive and marketing intelligence are both involved with the development of a logical program for gathering, examining and handling external information and knowledge to enhance organizational decision making capabilities. Marketing intelligence is focused on the organization's markets, whilst competitive intelligence is mainly focused on the competition.

The mining industry, like other organizations, uses information to expand and maintain competitive advantage in the current information age in which knowledge is power. Collecting information and transforming these raw data into intelligence is an essential aspect of business. By utilizing information systems when generating intelligence, the wealth of available information can enable mining organizations to achieve competitive advantage to survive and succeed in the long term.

Conclusions regarding the specific empirical objectives. The other main objective was to determine to what extent the different types of intelligence are used within the mining industry.

Results of the factor analysis showed that all the factors displayed satisfactory levels of reliability. More than half of the respondents indicated that their organizations do not have real-time intelligence. About $46 \%$ of the respondents do not have proper data mining tools to identify patterns and relationships within a data warehouse.

The other objective was to determine the relationship between the dimensions of intelligence and the performance. The results indicated that $60 \%$ of the organizations were not satisfied with the productivity of their current operations. The overall performance of $44 \%$ of the mines was not meeting expectations. About $30 \%$ of the mines indicated that their cash flows were not stable at all.

The results also confirmed that a statistically and practically significant positive relationship with a large effect exists between business intelligence, competitive intelligence and marketing intelligence dimensions, and business performance.

The data also indicated that mines in other continents use the different types of intelligence more than those in SA and the rest of Africa.

\section{Recommendations}

Based on the review of literature and the empirical data generated in this study, the researcher makes the following recommendations to the managers of the mining organizations. The recommendations are, generally, applicable to any industry:

- Organizations need to systematically and continuously collect information from their own internal business operations, the competitive environment, the competitors and the markets to assist in operational, tactical and strategic decision making.

- All forms of intelligence need to be distributed to management in a timely fashion.

- The organizations need to make an organized effort to channel all the information gathered from all types of intelligence to a central repository.

- The organization's information system should be tailored in such a way that it provides easy access to the required data.

- Intelligence tools used by the organizations should have forecasting abilities.

The intelligence activities are a key input variable in all strategic decision making. As organizations seek sustainable growth in global business, it is essential for them to have accurate and timely intelligence concerning threats and opportunities in the international business environment. This is the reason why organizations have been found to use various types of intelligence systems to gather and process this intelligence. The integration of business intelligence, competitive intelligence and marketing intelligence is recommended and should be enabled as a strategic function of the organization to inform and improve the decision making process of the managers. Some of the benefits of such convergence would be innovation, marketing differentiation, anticipating new markets, avoiding cost, customer satisfaction, winning market share, and revenue prospect. In general, mining organizations need to structure their data so that they can find answers easily, share timely information, make better business decisions, improve productivity and allow flexibility for future growth.

Participants in different geographic areas responded differently to the questions about intelligence dimensions and business performance. Possible reasons for this can be established by further research.

The researcher has made a proposal for the integration of different types of intelligence; generation of more empirical data to support this can also be done by further research.

\section{References}

1. Anica, I.P. \& Cucui, G. (2009). A framework for enhancing competitive intelligence capabilities using decision support system based on web mining techniques, International Journal of Computers, Communications \& Control, 
4 (4), pp. 326-334.

2. Buthelezi, N. (2013). Business intelligence can help mining overcome pressures. Available at: http://www.miningweekly.com/article/business-intelligence-is-a-process-that-can-help-alleviate-the-pressure-in-themining-industry-2013-06-14. Accessed on 20/02/2014.

3. Coker, F. (2014). Pulse: Understanding the Vital Signs of Your Business, Ambient Light Publishing, pp. 41-42.

4. Deloitte. (2014). Tracking the trends. Available at: http://www2.deloitte.com/content/dam/Deloitte/ global/Documents/Energy-and-Resources/dttl-er-Tracking-the-trends-2014_EN_final.pdf. Accessed on 14/11/2015.

5. Gartner. (2013). IT Glossary. Available at: http://www.gartner.com/it-glossary/business-intelligence-bi/. Accessed on $04 / 12 / 2014$.

6. Igbaekemen, G.O. (2014). Marketing intelligence as a strategic tool for competitive edge, British Journal of Marketing Studies, 2 (5), pp. 17-34.

7. Kotler, P., Keller, K.L., Koshy, A. \& Jha, M. (2009). Marketing management. $13^{\text {th }}$ ed.

8. Kruger, J. (2010). A study of strategic intelligence as a strategic management tool in the long-term insurance industry in South Africa. University of South Africa. Masters Dissertation.

9. Kumari, N. (2013). Business intelligence in a nutshell, International journal of innovative research in computer and communication engineering, 1 (4), pp. 969-975.

10. Mining Weekly. (2013). Company announcement: driving down production costs. Available at: $\mathrm{http} / / / \mathrm{www} \cdot \mathrm{miningweekly.com/article/company-announcement-driving-down-production-costs-2013-02-26.} \mathrm{Accessed}$ on $20 / 02 / 2014$.

11. Pellissier, R. \& Nenzhelele, E.T. (2013). Towards a universal definition of competitive Intelligence, SA Journal of Information Management, 15 (2), Art. \#559, 7 pages. Available at: http://dx.doi.org/10.4102/sajim.v15i2.559. Accessed on 01/12/ 2014.

12. Saunders, M., Lewis, P. \& Thornhill, A. (2009). Research methods for business students. 5th ed. Essex England: Prentice Hall.

13. Troy Media Marketplace. (2015). Business intelligence vs competitive intelligence. Available at: http://www.troymedia.com/2015/04/13/business-intelligence-vs-competitive-intelligence/. Accessed on 24/10/2015. 